\title{
Trabalho Docente com Estatística nos Primeiros Anos de Escolarização: um Estudo de Caso
}

\author{
Teaching Work with Statistics in the First Years of Schooling: a Case Study
}

\author{
Cíntia Poffo*a; Janaína Poffo Possamaia ${ }^{\text {; }}$ Viviane Clotilde da Silva ${ }^{a}$ \\ aUniversidade Regional de Blumenau, Pós-Graduação Stricto Sensu em Ensino de Ciências Naturais e Matemática. SC, Brasil. \\ *E-mail: poffocintia22@gmail.com
}

\begin{abstract}
Resumo
O letramento estatístico pode ser desenvolvido desde os primeiros anos de escolarização, envolvendo o contexto de brincadeira e de vida. Também, a análise e apresentação de dados que pode tomar como base a perspectiva de organização que as crianças já têm em mente. Nesse contexto, esse trabalho tem como objetivo analisar como é realizado o trabalho com estatística no pré-escolar e no primeiro ano do Ensino Fundamental em um município do interior de SC, com o intuito de, na continuação da pesquisa, desenvolver uma proposta de intervenção to no que se refere ao ensino de estatística, no primeiro ano do Ensino Fundamental. Esse é um estudo do tipo descritivo de análise qualitativa, sendo todos os professores da pré-escola e do primeiro ano do ensino fundamental que atuam na rede municipal em questão, entrevistados por meio de um questionário semiestruturado. A análise das entrevistas indica que os professores identificam a necessidade de desenvolver um trabalho que tenha como ponto de partida temáticas de interesse e do cotidiano das crianças. Também evidencia a importância de se conhecer verticalmente o currículo da Educação Infantil e do Ensino Fundamental, de modo a resgatar os conhecimentos prévios e então construir novos, com base nas conexões que as crianças conseguem estabelecer.
\end{abstract}

Palavras-chave: Letramento Estatístico. Prática Docente. Resolução de Problemas.

\begin{abstract}
Statistical literacy can be developed from the first years of schooling, involving the context of play and life, and the analysis and presentation of data can be based on the organizational perspective that children already have in mind. In this context, this work aims to analyze how work with statistics is carried out in pre-school and in the first year of elementary school in a city in the interior of SC, with the intention of, in the continuation of the research, developing an intervention proposal regarding the teaching of statistics, in the first year of elementary school. This is a descriptive type study of qualitative analysis, with all pre-school and first-year elementary school teachers working in the municipal network in question, interviewed using a semi-structured questionnaire. The analysis of the interviews indicates that the teachers identify the need to develop a work that has as a starting point themes of interest and the daily lives of children. It also highlights the importance of vertically learning the curriculum for Early Childhood Education and Elementary Education, in order to rescue previous knowledge and then build new ideas based on the connections that children are able to establish.
\end{abstract}

Keywords: Statistical Literacy. Teaching Practice. Problem Solving.

\section{Introdução}

Uma discussão sempre presente entre os educadores estatísticos e matemáticos se deve ao fato de muitas pessoas pensarem que Matemática e Estatística são o mesmo corpo de conhecimento, e, assim, confundirem o raciocínio estatístico com o matemático (Garfield \& Gal, 1999).

O letramento estatístico envolve o pensamento estatístico que se difere do pensamento matemático na medida em que "a estatística requer um tipo diferente de pensamento, porque os dados não são apenas números, são números com um contexto." (Franklin et al., 2007, p. 7, tradução nossa).

No cerne da Educação Infantil e do primeiro ano do Ensino Fundamental, desenvolver o letramento estatístico implica em relacionar o contexto de brincadeira, de curiosidade das crianças sobre si mesmas. Nesse ambiente a perspectiva de trabalho que atua nessa direção envolve uma participação ativa das crianças em processos de investigação, de coleta e análise dados, sem seguir o "modelo do professor", mas deixando-as decidir pela forma de organização, pelas perguntas que podem ser feitas e pelo que desejam investigar.

Com o intuito de realizar uma proposta de intervenção do que se refere ao ensino de estatística, no primeiro ano do Ensino Fundamental na rede municipal de ensino de uma cidade no interior de SC, investigou-se "como os professores do pré-escolar e do primeiro ano do Ensino Fundamental, de um município do interior de SC, trabalham estatística com as crianças". É importante salientar que os professores do préescolar foram incluídos na pesquisa visando conhecer se as crianças chegam no primeiro ano com algum conhecimento prévio sobre estatística e de que forma isso é incorporado no planejamento.

Assim, tem-se definido como objetivo desse estudo, analisar como é realizado o trabalho com estatística nas 
turmas e no município supracitado. Na sequência apresentase os preceitos que norteiam essa pesquisa e que orientam a análise dos dados.

\section{O Ensino de Estatística}

A estatística está presente em nossas vidas de várias formas. Somos submetidos constantemente a informações que exigem um olhar mais aguçado referente a análise de dados, permitindo-nos tomar decisões, muitas vezes importantes para atividades rotineiras, como por exemplo, pesquisa de preço. Para tanto, progressivamente, as pessoas necessitam saber ler e interpretar dados, pois esse conhecimento adquirido resultará em estratégias mais objetivas para a resolução de seus problemas (Fortes et al., 2019).

Com essa realidade, cada vez mais acentuada na atualidade, se faz necessário que a Estatística esteja presente nos currículos escolares, visto que, como afirmam Cazorla et al. (2017, p. 14), ela é uma "ciência do significado e uso de dados" utilizando-se de ferramentas para "obter, resumir e extrair informações relevantes de dados" auxiliando assim a tomada de decisão e a possibilidade de escolhas mais assertivas.

Nesse contexto, para que os adultos consigam compreender e utilizar a Estatística em suas vidas, é primordial que essa passe a ser desenvolvida em um processo contínuo na vida escolar e que, consequentemente, metodologias de ensino abordem a Educação Estatística desde a Educação Infantil e Anos Iniciais do Ensino Fundamental, objetivando ao longo do percurso, a formação de um cidadão crítico e com autonomia. Van de Walle (2009) completa que, para acontecer essa formação, as crianças devem ter contato com informações que envolvam Estatística desde pequenas, na qual a compreensão e o aprendizado irão evoluindo através de experiências informais até se constituírem de fato em aprendizagens com significado, possibilitando assim, a comunicação de informações presentes em gráficos.

Os tipos de atividades necessárias e apropriadas para os alunos da Educação Infantil variam muito daqueles do Ensino Fundamental; no entanto, durante os Anos Iniciais, os alunos devem fazer perguntas para investigar, organizar as respostas e criar representações de seus dados. Através de investigações de dados, os professores devem incentivar os alunos a pensarem com clareza e a verificarem novas ideias conectadas as que eles já sabem, a fim de desenvolver conceitos para tomarem decisões com base em informações. (NCTM, 2000, p. 109, tradução nossa).

Nesse percurso as crianças passam por um processo de formação integral, na qual irão desenvolver paralelamente e consequentemente algumas habilidades essenciais para a aplicação de ferramentas estatísticas. Essas habilidades perpassam por duas concepções, que estão interligadas aos primeiros anos do Ensino Fundamental: a Alfabetização Estatística e o Letramento Estatístico, que devem ser desenvolvidos, concomitantemente, em todas as áreas do conhecimento, possibilitando que as crianças consigam acompanhar e interagir com as demandas atuais da sociedade em que estão inseridas.

Os Parâmetros Curriculares Nacionais de Matemática definem alfabetização estatística como um conjunto de habilidades que permitem às crianças o desenvolvimento atitudinal de "ler e interpretar dados apresentados de maneira organizada e construir representações, para formular e resolver problemas que impliquem o recolhimento de dados e a análise de informações”. (Brasil, 1997, p. 84). Para tanto, a alfabetização estatística é uma habilidade essencial que deve ser desenvolvida na escola, permitindo que o cidadão seja capaz de decodificar símbolos, utilizando-se da linguagem estatística para se comunicar.

Todo o desenvolvimento desse processo de aprendizagem é contemplado nos currículos escolares da Educação Básica, já que a Base Nacional Comum Curricular - BNCC (Brasil, 2018), que orienta a construção destes, contempla a Estatística e a Probabilidade em uma das cinco unidades temáticas do componente curricular Matemática.

O letramento estatístico envolve a alfabetização estatística, portanto depois que a criança se apropria dos símbolos e linguagens passa a utilizá-los para interpretar e analisar informações que envolvem seu contexto, objetivando a tomada de decisão crítica baseada em dados reais. Para Gal (2002, p. 2, tradução nossa) o letramento estatístico é "uma habilidade-chave esperada de cidadãos em sociedades sobrecarregadas de informação, frequentemente vista como um resultado esperado da escolaridade e como componente necessário do letramento e da numerácia de adultos".

Reforçando o que já foi apresentado, para que as crianças sejam letradas estatisticamente, Watson (2006) aponta que a Educação Estatística deve estar contemplada nos currículos da Educação Infantil e dos Anos Iniciais, utilizando de dados reais em atividades práticas ou experimentais, que auxiliarão no desenvolvimento de um cidadão crítico, sendo assim, o autor aponta quatro premissas essenciais para o planejamento destas:

$>$ A construção do letramento estatístico deve ocorrer dentro do currículo escolar, principalmente na área de conhecimento matemático, a fim de fazer conexões com outras áreas do conhecimento para reforçar e aprimorar a aprendizagem. As conexões devem ser feitas em contextos onde é possível a utilização de informações e dados reais.

$>\mathrm{O}$ letramento estatístico deve estar conectado com as habilidades de letramento, pensamento crítico, compreensão do contexto e deliberação.

$>\mathrm{O}$ desenvolvimento do letramento estatístico ocorre com o tempo em um processo contínuo e progressivo. $\mathrm{O}$ planejamento deve conter experiências de aprendizagem, no qual as crianças utilizem seus conhecimentos prévios para o desenvolvimento de uma maior compreensão conceitual ao final da experiência.

$>$ São necessárias atividades adequadas para o desenvolvimento conceitual sobre dados e probabilidade, sendo o contexto essencial para o desenvolvimento do pensamento crítico. 
Essas premissas, quando contempladas em um planejamento que valorize a autonomia e o espírito investigativo das crianças, desenvolverão o pensamento estatístico, sendo este "a capacidade utilizar e/ou interpretar, de forma adequada, as ferramentas estatísticas na solução de problemas". (Cazorla et al., 2017, p. 15). Além disso, o pensamento estatístico é definido por Lopes (2012, p. 169) como sendo a:

[...] capacidade de relacionar dados quantitativos com situações concretas, admitindo a presença da variabilidade e da incerteza. A exploração de processos investigativos, como pesquisas de opinião, permitirá às crianças exercitar a escolha adequada de ferramentas estatísticas. Adquirir essa capacidade também faz parte do pensar estatisticamente, assim como vivenciar todas as etapas do processo de investigação estatística, explorando os dados de forma a estabelecer relações que respondam a questão investigada ou gerem outros questionamentos.

O trabalho, na Educação Infantil e nos Anos Iniciais do Ensino Fundamental, deve partir das vivências concretas, para que ao final do processo, esse conhecimento possibilite as crianças contribuições significativas para sua formação e que quando adultos, exerçam na sociedade, seu papel de cidadãos com autonomia e criticidade.

Visto a garantia da inserção deste conhecimento nos currículos, o seu desenvolvimento deve ser contemplado e estar alinhado com o planejamento do professor, para que, sejam dadas oportunidades de aprendizagem e de construção do conhecimento por parte da criança, partindo de problematizações existentes no seu cotidiano, dando à elas a autonomia para pesquisar, analisar, interpretar e debater os resultados. "Acredita-se que se o professor conseguir, em sua prática pedagógica, oportunizar essa autonomia, estará contribuindo para a construção da aprendizagem Estatística" (Votto, Schereiber \& Porciúncula, 2017, p. 147).

\section{Análise e Discussão}

Com a finalidade de analisar como é realizado o trabalho com no pré-Escolar e no primeiro ano do Ensino Fundamental em um município do interior de $\mathrm{SC}$, foi realizada uma entrevista com quatro professoras colaboradoras, sendo que duas lecionam para o pré-Escolar e duas para o primeiro ano do Ensino Fundamental. É importante ressaltar que a entrevista não representa uma amostra, mas sim a totalidade de professores que a rede municipal de ensino tem nesses níveis.

Essa pesquisa se caracteriza como descritiva, pois irá descrever a prática realizada pelas professoras quanto à Educação Estatística. Para tanto, a coleta de dados foi realizada por intermédio de uma entrevista semiestruturada e as respostas foram registradas por meio de gravações (Kauark, Manhães \& Medeiros, 2010).

Quanto à natureza, a pesquisa é categorizada como qualitativa, por conta que "a interpretação dos fenômenos e a atribuição de significados são básicas" nesse processo.
(Kauark, Manhães \& Medeiros, 2010, p. 26). A entrevista foi elaborada com o objetivo de extrair dados que possam ser analisados, relacionando-os a alguns referentes teóricos da área, auxiliando na descrição e reflexão de como as professoras ensinam estatística para as crianças.

Analisando a coleta de dados, é possível verificar que as práticas pedagógicas das professoras estão pautadas na participação ativa das crianças, o que pode ser observado na fala de uma das professoras que indica desenvolver a "construção do conhecimento juntamente com as crianças" e de outra que revela possibilitar que as crianças "construam seu próprio conhecimento". Nas falas é notável que a apropriação do conhecimento ocorre de forma coletiva, na qual todas as crianças, ao seu tempo, têm a possibilidade de contribuir e aprender. $\mathrm{O}$ relato das professoras vem ao encontro da indicação de que "todos os estudantes devem ter a oportunidade e o apoio necessário para aprender [...] com profundidade e compreensão" (NCTM, 2000, p. 50, tradução nossa), sendo necessário o envolvimento da criança em todo o processo, na qual elas possam trabalhar coletivamente e de forma ativa explorando seus conhecimentos prévios para o desenvolvimento de novas experiências.

Nessa mesma perspectiva de construção de conhecimento, algumas professoras afirmam que ao utilizar uma abordagem que dê mais autonomia e espaço às crianças, estimula seu desenvolvimento profissional, pois essa exige do professor constante pesquisa e criatividade, como citam três colaboradoras: "estamos sempre aprendendo mais ao desenvolver nosso trabalho", "busco inovações ou outros meios para que as crianças alcancem ao máximo o conhecimento", busco informações e métodos para suprir as necessidades de uma educação de qualidade”. A formação do professor é essencial para subsidiar sua prática pedagógica, essa por sua vez é bastante pessoal, pois irá se moldando e se modificando com as experiências vivenciadas na docência, permitindo um melhor alinhamento entre teoria e prática. Para Lopes (2003, pp. 27-28) o professor, diariamente, em sua prática pedagógica,

[...] defronta-se com múltiplas situações para as quais não encontra respostas preestabelecidas. Para fazer-lhes face, tem de pôr em movimento um conhecimento que envolve elementos com origens diversas - incluindo acadêmicas e experiências - , bem como aspectos de foro pessoal e contextual. Em seu desempenho profissional, o docente não só precisa mobilizar teorias e técnicas, mas também suas concepções, sentimentos e seu saber-fazer. É por isso que cada vez mais se identifica o conhecimento do professor como prático, pois integra conhecimento teórico de referência e experiencial. É pessoal, porque é construído pelo próprio docente, inserido nos vários contextos de sua atuação profissional.

Referente às aulas de matemática, é possível identificar que todas as professoras utilizam materiais manipulativos como ferramenta de apoio para o desenvolvimento de uma aprendizagem com significado. Lopes (2003) afirma que a manipulação desses materiais é muito importante nesta 
etapa de ensino, pois eles oportunizam o desenvolvimento do pensamento abstrato.

Porém, Van de Walle (2009) faz algumas advertências relacionadas a utilização desses materiais nas aulas, indicando que eles só terão eficácia se o professor deixar que as crianças os explorem livremente, sem regras pré-estabelecidas, pois partindo da experiência com estes, é que surgirão as respostas, as novas ideias e a construção do conhecimento. $\mathrm{O}$ autor apresenta algumas indicações de utilização desses materiais como ferramenta de auxílio a aprendizagem,

Os modelos sempre devem estar acessíveis aos estudantes para escolha e uso livre. Uma variedade de modelos deve estar disponível para ajudar com uma ideia importante. Os estudantes devem ser encorajados a selecionar e usar materiais que os ajudem a trabalhar em um problema ou explicar uma ideia ao seu grupo. Devem selecionar modelos que façam sentido para eles. E não é correto forçar os estudantes a usar um modelo particular. (Van de Walle, 2009, p. 53).

Além desses materiais, as professoras citam outras estratégias utilizadas para desenvolver matemática com as crianças: "brincadeiras, jogos, exemplos práticos de sala de aula, atividades orais, situações de contagem e situações problemas". Esta prática vai ao encontro do apresentado na BNCC (Brasil, 2017) que sugere que a Matemática seja integrada as outras áreas do saber por meio de estratégias de resolução de problemas que desenvolverão as linguagens matemáticas, o raciocínio, a criatividade e a imaginação. Assim, vale ressaltar que

Os professores eficientes têm de ajudar os estudantes a construir suas próprias ideias usando as que eles já possuem. Isso não significa que nós simplesmente deixamos os estudantes brincarem e esperamos que eles descubram magicamente novas ideias matemáticas. Pelo contrário, a maneira pela qual uma turma é gerenciada, o clima social que é estabelecido dentro da sala de aula e os materiais disponibilizados para os estudantes explorarem - tudo tem um impacto enorme sobre o que é ensinado e o quão bem é compreendido. (Van de Walle, 2009, p. 48).

Corroboram Toledo e Lopes (2019, pp. 46-47) quando afirmam que a resolução de problemas deve fazer parte do planejamento diário do professor e devem ser incentivados o diálogo e a exposição de ideias nessas atividades, pois elas "dão aos alunos a oportunidade de confrontar-se com diferentes opiniões, colocações e ensinam os estudantes a ouvir os colegas e a valorizar sua própria opinião, bem como as de outros". Uma das professoras salienta que trabalha com resolução de problemas para que as crianças "tenham oportunidade e consigam escolher suas próprias estratégias para futuramente resolver seus problemas, pois em meio a tanta informação, eles precisam desenvolver habilidades para analisar, organizar, interpretar e tirar suas próprias conclusões".

Sobre resolução de problemas, Van de Walle (2009) salienta a necessidade de o professor confiar e dar oportunidade às crianças, deixando que elas tentem encontrar soluções, que discutam suas ideias e que aprendam com os erros.
Uma vez que seus alunos estejam preparados para trabalhar na tarefa, é o momento de deixá-los caminhar. Demonstre confiança e respeito pelas habilidades deles. Coloque-os para trabalhar com a expectativa de que eles resolverão o problema. Você tem que deixá-los caminhar! Muitos professores são tentados a caminhar lado a lado e ajudá-los, "colocando a carroça à frente dos bois" e fornecendo instruções inconvenientes. Tenha confiança em seus alunos! Deixe-os resolver o problema. Isto pode ser muito difícil para você, pois provavelmente escolheu ensinar para "ajudar" os alunos. Agora você precisa deixá-los caminhar sozinhos. Deixar caminhar também significa permitir que eles cometam erros. (Van de Walle, 2009, p. 65).

Tratando-se especificamente de Educação Estatística, é possível perceber algumas características semelhantes nas práticas pedagógicas desenvolvidas nessa etapa de ensino e aprendizagem pelas professoras entrevistadas, na qual as mesmas se assemelham as estratégias aplicadas para o desenvolvimento da matemática. É evidente em seus depoimentos a utilização de recursos lúdicos por parte de todas as professoras como "jogos, atividades recreativas" e elaboração de "sequências didáticas".

Como já citado esses recursos precisam ser usados com intencionalidade para atender aos objetivos de aprendizagem, os questionamentos e diálogos devem ser incentivados para gerar discussão, pensamento e desenvolvimento de aprendizagem. Algumas professoras afirmam incentivar os diálogos por meio de "questionamentos, comparações orais, rodas de conversa e oportunidade de opinar" outra professora ainda completa que "as crianças precisam ser oportunizadas a pensar, falar, expor suas ideias e chegar a uma conclusão".

Esse momento de questionamentos e trocas de experiência entre as crianças é muito rico, pois nestas conversas é que acontece a conexão de ideias. Uma das professoras cita que o objetivo de trabalhar bastante a oralidade é fazer com que as “crianças participem e opinem, e que mesmo errando tenham a oportunidade de falar, demonstrando assim sua autonomia. De tal modo as aulas ficam mais prazerosas onde não só o professor fala". Nesse sentido, enfatiza-se a importância de os professores incentivarem e deixarem que esse momento aconteça livremente, pois "quando os professores respondem habitualmente com 'Sim, isso está correto.' ou 'Não, isso está errado.', os estudantes deixam de tentar dar significado às ideias e a discussão e a aprendizagem serão reduzidas em sala de aula" (Van de Walle, 2009, p. 50).

Nas entrevistas, é possível identificar outras estratégias usadas para o desenvolvimento de Educação Estatística, tais como: "registro de respostas, situações problemas, coleta de informações, interpretação, construção de gráficos e tabelas" e gráficos baseados em observações diárias, como por exemplo, "gráfico do tempo".

São várias as situações no dia a dia que oferecem dados que podem ser investigados, organizados e interpretados pelos alunos. [...] As situações-problema podem ser sugeridas pelo professor ou pelos alunos, o importante é que durante todo o processo o aluno participe das discussões e seja o protagonista da ação de organizar os dados na tabela ou no 
gráfico, observando que variáveis devem ser consideradas e onde colocar as informações e dados. Na fase de interpretar os dados, é importante que se questionem os dados, levantando aspectos importantes na comparação das informações. (Vilas Bôas \& Conti, 2018, p. 998).

Nessa etapa de ensino em que as crianças se encontram é bastante significativo o trabalho com o registro, pois elas estão na fase de alfabetização passando a reconhecer a função social da escrita. Ele auxilia as crianças a perceberem o processo de como se deu o raciocínio para resolução de tal atividade, por isso é importante a variação das formas de registro (individual, pequenos grupos, coletivo - professor pode ser escriba) e do material utilizado (caderno, folha, cartazes, papel, escrita, desenho, recorte).

Lopes e Mendonça (2016, p. 303) reforçam a importância de as crianças terem "a oportunidade de realizar perguntas da pesquisa, de criar métodos de coleta de dados e folhas de registro". As autoras ainda reforçam a importância de registros coletivos, sobre as investigações ou experiências, que sejam divulgados no ambiente em que as crianças estão inseridas, assim perceberão a importância da estatística em seu meio social.

Referente ao desenvolvimento do pensamento estatístico, as professoras estão alinhadas com o que os teóricos almejam. Todas consideram esse importante para possibilitar a "formação de um cidadão crítico que pensa, opina e questiona". Algumas ainda justificam a importância de se desenvolver o pensamento estatístico para que as crianças aprendam a "analisar informações" e "tomar decisões e fazerem suas próprias escolhas". Para tal desenvolvimento uma das professoras cita "priorizar o trabalho com gráficos de forma simples e concreta utilizando exemplos práticos do cotidiano das crianças".

É importante frisar que a Educação Estatística vai muito além da construção de gráficos, há todo um processo de construção de conhecimento que é desenvolvido antes, durante e depois dessa construção. Depois de pronto o gráfico não pode se resumir em apenas identificar a coluna maior e a menor ou realizar algumas operações baseando-se nos dados. A interpretação pode partir também de questionamentos feitos pelo professor ou pelas próprias crianças.

Quando os dados são exibidos de maneira organizada, as discussões em classe devem se concentrar em o que o gráfico ou outra representação transmite e se os dados ajudam a responder às perguntas específicas para as que foram colocados. Os professores devem incentivar os alunos a comparar partes dos dados ('O mesmo número de crianças tem cães e gatos') e fazem declarações sobre o todo ('A maioria dos alunos da turma perdeu apenas dois dentes'). (NCTM, 2000, p. 113, tradução nossa).

Atividades que envolvam experiências concretas, investigação e pesquisa de opinião possibilitam o desenvolvimento do pensamento estatístico abrindo possibilidades para a construção do conhecimento e aplicação de ferramentas estatísticas (Vilas Bôas \& Conti, 2018).
As professoras percebem que as crianças utilizam estatística em situações de seu cotidiano, muitas vezes, sem um direcionamento para tal atividade. Na hora do brincar e da socialização com o outro é que essas situações se destacam, uma das professoras salienta que "quando a criança inventa, organiza, compara, analisa tamanhos ao construir torres com peças de Lego ou seleciona brinquedos, está sempre fazendo suas escolhas e tirando suas próprias conclusões".

$\mathrm{Na}$ Educação Infantil e nos Anos Iniciais do Ensino Fundamental é relevante proporcionar espaços e experiências de aprendizagem prazerosas, no qual as crianças possam aprender matemática e estatística brincando, se expressando, socializando, experimentando e mostrando. "A criança tem direito a um conhecimento matemático que está presente em seu mundo imaginário e em seu mundo real. Ela tem direito a pensar e estabelecer relações dessa matemática com o desvendar de sua vida. A criança lê o mundo e questiona o que vê” (Lopes, 2012, p. 164).

Para asseverar as respostas das professoras de uma maneira visual, na Figura 1, está expresso em forma de uma nuvem de palavras as que mais se destacaram, pela frequência na entrevista. Seguiu-se a lógica de que quanto maior a palavra na nuvem, maior a frequência com que esta apareceu na entrevista.

Figura 1 - Nuvem de Palavras

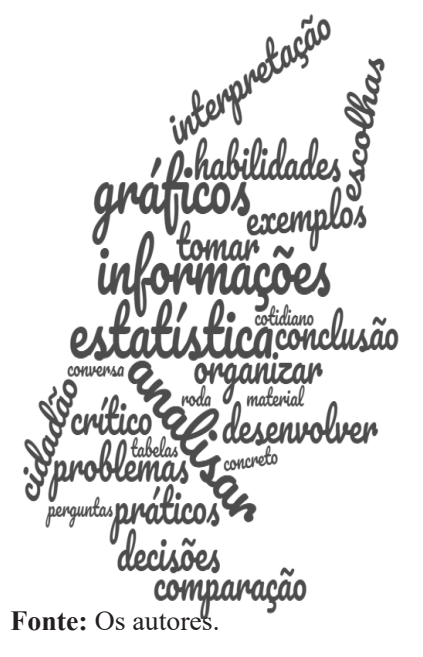

Como síntese dessa análise pode-se evidenciar (inclusive na Figura 1) que o entendimento da estatística como números em um contexto, respeitando e inserindo a realidade das crianças, é assegurado na prática dos professores entrevistados. Porém, o que transparece nesse percurso é um processo progressivo na organização e apresentação de dados, por meio de gráficos e tabelas. Os professores indicam utilizar gráficos e envolver as crianças na organização dos dados e na construção de gráficos para representá-los, porém não há indicação de que essa inserção se dê de forma gradual - inicialmente com objetos concretos representando os dados, com representação usando desenhos, com organização na malha quadriculada e por fim, com números em eixos legendados indicando os resultados. 
Assim, acredita-se que este estudo de caso possa mobilizar o desenvolvimento de pesquisas futuras que envolvam o entendimento da construção progressiva do registro dos dados, envolvendo as ideias das crianças como forma primordial para fazer essas conexões.

\section{Conclusão}

Diversos autores e, também, documentos orientadores, indicam que a Educação Estatística deve estar contemplada nos currículos escolares e nas práticas pedagógicas dos professores da Educação Infantil e dos Anos Iniciais do Ensino Fundamental. Nesse sentido, a formação didática dos professores que ensinam Estatística é primordial para que de fato, o pensamento estatístico seja desenvolvido, pois "a ausência dessa formação específica pode ser o motivo, muitas vezes, para não se dar a devida importância à temática, levando a um trabalho com ênfase maior em números e operações, por exemplo. (Vilas Bôas \& Conti, 2018, p. 1001)

É recomendável que quando os professores não se sintam preparados procurem subsídios para suprir essa lacuna de seu percurso formativo. Algumas das possibilidades são: as formações continuadas, buscar orientação nos documentos norteadores dos currículos escolares, trocas de ideias e experiências com colegas de trabalho ou outros profissionais, buscar orientação com profissionais formados na área ou até mesmo uma complementação na graduação, nova graduação, especialização ou mestrado. O importante é o professor ter esse conhecimento bem consolidado para poder trabalhar com as turmas de atuação.

Os resultados dessa pesquisa evidenciam que há muitas possibilidades de desenvolver Educação Estatística nessa etapa da educação, porém se torna mais prazeroso para as crianças quando esse trabalho parte de algum interesse deles, na qual possibilita-se que percebam a estatística em seu meio tendo contato assim, com diferentes formas de comunicação de dados.

A elaboração e execução de uma prática tal qual proposta na $\mathrm{BNCC}$ requer que se pense um contexto de aprendizagem que situe a criança em um ambiente de atividade matemática, estatística e probabilística, que possibilite que ela aprenda, além de codificar e decodificar os símbolos matemáticos, a realizar diversas leituras de mundo, levantar conjecturas e validá-las, analisar dados e argumentar sendo capaz de justificar os procedimentos, decida sobre o que pesquisar, como produzir, como coletar dados e organizá-los, bem como escolher como apresentá-los. (Vilas Bôas \& Conti, 2018, p. 1001)

Retomando o objetivo de pesquisa, tem-se que a utilização do contexto da criança, no desenvolvimento das práticas dos professores entrevistados, é evidenciada pelos relatos apresentados, porém ainda carece de utilização de recursos diversos (material manipulativo, desenho, representação numérica) para ampliar continuamente o nível de complexidade e compreensão da organização e apresentação de dados estatísticos.
É importante que os professores tomem conhecimento do currículo das outras turmas também, pois na Educação Estatística os objetivos de aprendizagem se ampliam a cada etapa, sendo contínuo e progressivo, tornando essencial que em cada etapa esses estejam bem consolidados. Para tanto, desde a Educação Infantil, é importante proporcionar às crianças experiências significativas em relação a Educação Estatística, permitindo a compreensão de utilização das ferramentas estatística em seu percurso escolar.

Por fim, acredita-se que essa pesquisa forneceu dados para que se possa acompanhar os professores no desenvolvimento de sequências didáticas, que contemplem a perspectiva de brincadeira e de conhecer das crianças, mas que também envolvam a construção progressiva e com significado das ferramentas usadas em estatística para representação e análise de dados, evidenciadas no estudo como um lacuna a ser preenchida.

\section{Agradecimentos}

Ao Programa UNIEDU/FUMDES Pós-Graduação pela concessão da Bolsa de Pesquisa à Cintia Poffo, que muito tem auxiliado a realizar nossas pesquisas.

\section{Referências}

Brasil. (2017). Base nacional comum curricular. Brasília: MEC.

Brasil. (1997). Parâmetros curriculares nacionais: matemática. Brasília: Ministério da Educação, Secretaria de Educação Fundamental.

Cazorla, I.; Magina S., Gitirana V. \& Guimarães G. (2017). Estatística para os anos iniciais do ensino fundamental. Brasília: Sociedade Brasileira de Educação Matemática.

Franklin, C. A., Kader, G., Mewborn, D., Moreno, J., Peck, R., Perry, M., \& Scheaffer, R. (2007). Guidelines for assessment and instruction in statistics education (GAISE) report: A pre-K-12 curriculum framework. Alexandria, VA: American Statistical Association.

Fortes, L. S.; Lemos, M. P. F. de; Santos; K. R. dos \& Sousa S. C. Jr. (2019). Trabalhando com estatística no ensino fundamental. In: LOPES, C. S.; Porciúncula, M. \& Samá, S. (Orgs.), Perspectiva para o ensino e a aprendizagem de estatística e probabilidade. (Cap. 3, pp. 71-90). São Paulo: Campinas.

Gal, I. (2002). Adults' statistical literacy: meanings, components, responsibilities. International statistical review, 70(1), 1-25. doi: 10.1111/j.1751-5823.2002.tb00336

Garfield, J. B. \& Gal I. (1999). Assessment and statistics education: Current challenges and directions. International Statistical Review, 67(1), 1-12. doi: 10.1111/j.17515823.1999.tb00377

Kauark, F. S., Manhães, F. C. \& Medeiros, C. H. (2010). Metodologia da pesquisa: Um guia prático. Itabuna: Via Litterarum.

Lopes, C. A. E. (2003). O conhecimento profissional dos professores e suas relações com estatística e probabilidade na educação infantil. (Tese de Doutorado). Universidade 
Estadual de Campinas, Faculdade de Educação, Campinas, SP, Brasil.

Lopes, C. A. E. \& Mendonça, L. (2016). Prospectivas para o estudo da probabilidade e da estatística no ensino fundamental. Revista Vidya, 36(2), 293-314. doi: 10.37781/ vidya.v36i2.1814

Lopes, C. A. E. (2012) A educação estocástica na infância. Revista Eletrônica de Educação, 6(1), 160-174. doi: $10.14244 / 19827199396$

NCTM. (2000) Principles and standards for school mathematics. Reston, VA: National Council of Teachers of Mathematics.

Toledo, S. E. R. G. O. \& Lopes, C. A. E. (2019). O ensino da estocástica: um desafio para os anos iniciais do ensino fundamental. In: LOPES, C. S.; Porciúncula, M. \& Samá, S. (Orgs.), Perspectiva para o ensino e a aprendizagem de estatística e probabilidade. (Cap. 2, pp. 42-70). São Paulo: Campinas.

Van de Walle, J. A. (2009) Matemática no ensino fundamental: Formação de professores e aplicações em sala de aula (6a ed.). Porto Alegre: Artmed.

Vilas Bôas, S. G.; \& Conti, K. C. (2018). Base nacional comum curricular: um olhar para estatística e probabilidade nos anos iniciais do ensino fundamental. Ensino Em Re-Vista, 25, 9841003. doi: 10.14393/ER-v25n3e2018-8

Votto, T., Schreiber, K. P. \& Porciúncula, M. (2017). Educação estatística nos anos iniciais do ensino fundamental. Caderno de Pesquisa, 24, 143-158. doi: 10.18764/2178-2229.v24n. especialp143-158

Watson, J. M. (2006). Statistical literacy at school: Growth and goals. Mahwah-NJ: Lawrence Erlbaum. 